\title{
PENGARUH KREDIT, LAMA USAHA DAN JUMLAH PEGAWAI TERHADAP JUMLAH PRODUKSI USAHA MIKRO KECIL MENENGAH DI KOTA TARAKAN
}

\author{
THE INFLUENCE OF CREDIT, AGE OF BUSINESS AND NUMBER OF \\ OFFICER TO NUMBER OF PRODUCTION OF MICRO AND SMALL \\ BUSINESS IN TARAKAN.
}

\author{
Syaiful Anwar ${ }^{1)}$, Tasdik Mubarok ${ }^{2)}$ \\ ${ }^{1) 2}$ Universitas Borneo Tarakan
}

\begin{abstract}
Abstrak : Tujuan dari penelitian ini adalah untuk mengetahui dan menjelaskan pengaruh kredit, panjang bisnis dan jumlah karyawan terhadap total produksi usaha mikro, kecil dan menengah di kota Tarakan secara parsial dan simultan. Studi ini menggunakan pendekatan kuantitatif, yaitu distribusi kuesioner bay ke pemilik usaha mikro kecil dan menengah di kota Tarakan yang berspesialisasi dalam memproduksi makanan dengan produk kemasan. sampel sebanyak 48 responden menggunakan rumus fungsi waktu linier karena jumlah usaha mikro kecil dan menengah yang memiliki kredit tidak diketahui. Alat analisis dalam penelitian ini menggunakan regresi linier berganda. Hasil penelitian ini menunjukkan bahwa secara parsial variabel kredit dan lama usaha berpengaruh positif dan signifikan terhadap jumlah produksi usaha mikro kecil dan menengah di kota Tarakan. Namun, variabel jumlah karyawan tidak memiliki pengaruh yang signifikan terhadap jumlah produksi usaha mikro kecil dan menengah di kota Tarakan. Namun, hasil penelitian secara simultan menunjukkan bahwa variabel kredit, lama karyawan berpengaruh positif dan signifikan terhadap jumlah produksi usaha mikro kecil dan menengah di kota Tarakan.
\end{abstract}

Kata kunci: Panjang Bisnis, Jumlah Karyawan, Jumlah Produksi, Kredit

Abstract : The purpose of this study is to find out and explain the effect of credit, length of busines and number of employees on the total production of micro, small and medium enterprises in the city of Tarakan in a partian and simultaneoud manner. This studi uses a quantitative approach, namely bay questionnaire distribution to small and medium-sized micro business owners in the city of Tarakan who are specialized in producing food with packaging products. a sample of 48 respondents using a linear time function formula because the number of small and medium micro businesses that have unknown credit. The analytikal tool in this study uses multiple linear regression. The result of this study indicate that partially the credit variables and the length of business have a positive and significant effect on the amount of production of small and medium micro enterprises in the city of Tarakan. However, the variable number of employees does not have a significant influece on the amount of production of small and medium micro enterprises in the city of Tarakan. However, the results of the study simultaneously show that the variables of credit, length of employees 
positively and significanly influence the amount of production of small and medium micro enterprises in the city of Tarakan

Keywords: Length of Business, Number of Employees, Amount of Production, Credit

\section{LATAR BELAKANG}

Usaha Mikro Kecil Menengah (UMKM) merupakan salah satu bagian penting bagi perekonomian suatu negara maupun daerah, karena kondisi ekonomi yang belum kondusif, pengembangan kegiatan usaha kecil dan menengah dianggap sebagai salah satu alternatif penting yang mampu mengurangi beban perekonomian yang dihadapi nasional maupun daerah. Besarnya peranan usaha mikro kecil menengah mengindikasikan bahwa umkm merupakan sektor usaha dominan dalam menyerap tenaga kerja serta berperan dalam proses pemerataan dan peningkatan pendapatan masyarakat.

Sektor umkm juga memberikan kontribusi yang sangat penting bagi perekonomian Indonesia ketika terjadi krisis, dimana umkm memiliki daya tahan menghadapi krisis ekonomi yang terjadi karena umkm tidak banyak memiliki ketergantungan pada faktor eksternal seperti hutang dalam valuta asing dan bahan baku impor dalam melakukan kegiatan operasionalnya. (Malik 2008)

Kondisi suatu daerah sangat berperan penting bagi pertumbuhan umkm dikarenakan perlu adanya dukungan dari berbagai sektor diantaranya dari mulai bahan baku, permodalan, pemasaran hingga kualitas manusianya sendiri. Kota Tarakan sangat berpotensi bagi pembentukan umkm dikarenakan satu-satunya Kota di Kalimantan Utara ini memiliki sumber bahan baku yang sangat melimpah dari mulai sektor pertanian, perikanannya ditambah lagi Kota Tarakan merupakan tempat transitnya masyarakat yang akan menuju daerah-daerah yang ada di Kalimantan Utara, sehingga pemasaran produk umkm sangat potensial baik pemasaran di Kota Tarakan sendiri maupun memasarkan produknya ke daerah-daerah lainnya. Pertumbuhan umkm di Kalimantan Utara dari tahun-ketahun selalu meningkat khususnya di Kota Tarakan yang tercatat seluruh jenis umkm di Dinas Perdagangan Koprasi dan UMKM tahun 2017 berjumlah 1.340 usaha mikro, 2.373 usaha kecil, dan 218 usaha menengah. Dengan meningkatnya umkm dari setiap tahun berdampak pada peningkatan penyerapan tenaga kerja serta meningkatnya pemodalan untuk memenuhi kebutuhan modal pelaku umkm sendiri, di Kota Tarakan sendiri sektor jasa sangat berperan dengan banyaknya lembaga keuangan dari mulai Bank dan Non Bank, koprasi simpan pinjam dan sebagainya yang bisa membantu permodalan dalam berupa kredit.

Kredit sangat diperlukan bagi pelaku umkm sendiri baik untuk mengembangkn usahanya maupun untuk memulai membuka usaha, dengan itu banyak produk-produk yang ditawarkan oleh lembaga 
keuangan, dengan kredit jangka pendek maupun jangka panjangnya, dengan jumlah angsuran yang berbeda pula, sehingga pelaku umkm bisa mengembangkan usahanya dengan begitu pendapatan usahanya akan meningkat dan penyerapan tenaga kerja akan meningkat pula.

Pendapatan usaha mikro kecil menengah sangatlah berpengaruh terhadap keberlangsungan dan perkembangan umkm sendiri, dengan itu kegiatan produksi harus dibarengi dengan hasil produksi yang tinggi, sehingga umkm membutuhkan modal dana tambahan berupa kredit dari berbagai perbankan maupun pihak lainnya, sehingga pelaku umkm bisa mengembangkan usahanya dimulai dengan teknologi pengolaha yang moderen sehingga hasil produksi memiliki kualitas yang tinggi dan watu pengolahan bisa lebih efisien.

Keberlangsungan UMKM sendiri di sisi lain dipengaruhi dengan ide-ide kreatif yang baru sehingga hasil produksi umkm lebih banyak dan unik, dimana umkm bisa bersaing di pasaran dan membuat konsumen lebih tertarik untuk membelinya Dibutuhkan pengalaman berwira usaha yang lama dan ilmu berwira usaha yang mempuni sehingga bisa mengontrol daya saing dengan produk-produk umkm lainnya.

\section{RUMUSAN MASALAH}

Adapun rumusan masalah dalam penelitian ini adalah :

1. Apakah kredit, lama usaha dan jumlah pegawai berpengaruh terhadap jumlah produksi usaha mikro kecil menengah di Kota Tarakan secara parsial ?

2. Apakah kredit, lama usaha dan jumlah pegawai berpengaruh terhadap jumlah produksi usaha mikro kecil menengah di Kota Tarakan secara simultan?

\section{TUJUAN PENELITIAN}

Tujuan penelitian ini adalah untuk mengetahui pengaruh kredit, lama usaha dan jumlah pegawai terhadap jumlah produksi usaha mikro kecil menengah di Kota Tarakan.

\section{TINJAUAN PUSTAKA}

Menurut Sukirno (2005), Teori produksi yang sederhana menggambarkan tentang hubungan diantara tingkat produksi suatu barang tersebut. Dalam analisis tersebut dimisalkan bahwa faktorfaktor produksi lainnya adalah tetap jumlahnya, yaitu modal dan tanah jumlahnya dianggap tidak mengalami perubahan dan juga teknologi tidak mengalami perubahan. Satu-satunya faktor produksi yang dapat diubah jumlahnya adalah tenaga kerja.

Dalam pengertian ekonomi produksi adalah sebagai suatu kegiatan yang secara langsung atau tidak langsung dapat menghasilkan barang dan jasa atau menaikan untility dari barang-barang ekonomi. Produksi adalah kegiatan atau proses yang menimbulkan manfaat atau penciptaan manfaat baru. (Hendro, 2011).

Menurut (Suratiyah, 2006), menyatakan bahwa jika permintaan akan produksi tinggi maka harga 
ditingkat usaha akan tinggi pula, sehingga dengan biaya yang sama akan memperoleh pendapatan yang lebih tinggi. Sebaliknya, jika telah berhasil meningkatkan produksi tetapi harga turun maka pendapatan akan turun pula.

Dalam praktisnya kredit yang di berikan bank umum dan bank pengkreditan rakyat untuk masyarakat terdiri dari berbagai jenis. Secara umum jenis-jenis kredit dapat di lihat dari berbagai segi antara lain, (Kasmir, 2006).

Lama pembukaan usaha dapat mempengaruhi tingkat pendapatan, lama seorang bisnis menekuni bidang usahanya akan mempengaruhi produktivitasnya sehingga dapat menambah efisiensi dan menekan biaya produksi lebih kecil dari pada penjualan (Firdaus, 2013).

Faktor produksi terdiri atas tenaga kerja, modal, sumber daya alam, dan teknologi. Ini berarti tenaga kerja merupakan salah satu faktor terpenting yang menentukan produksi. Karena tanpa adanya tenaga kerja kegiatan produksi tidak dapat berjalan. (simanjuntak dalam Setyaningrum, 2015).

Secara umum, karakteristik UMKM yang ada di ndonesia kebanyakan berbentuk industri mikro yang beroprasi pada level rumahan dengan teknologi rendah dan tenaga kerja yang berpendapatan rendah dan berkemampuan rendah (Tambuan, 2009).

\section{METODE PENELITIAN}

\section{$\underline{\text { Desain Penelitian }}$}

Penelitian ini merupakan jenis penelitian kuantitatif dengan metede survei dan studi pustaka, teknik pengumpulan data yang digunakan adalah menggunakan angket atau kuesioner yang merupakan pertanyaan tertulis yang dapat digunakan untuk memperoleh informasi dari responden dalam arti laporan tentang pribadi atau hal-hal yang ia ketahui.

Adapun topik dalam penelitian ini yaitu jumlah kredit, lama usaha dan jumlah pegawai usaha mikro kecil menengah olahan makanan di Kota Tarakan yang hasil produksinya menggunakan kemasan serta umkm yang memiliki kredit, Lokasi penelitian dilaksanakan di Kota Tarakan.

\section{$\underline{\text { Definisi Operasional }}$}

Untuk memperoleh gambaran yang jelas dalam pengumpulan data dilapangan rumusan secara operasional mengenai indikatorindikator yang akan diteliti. Hal ini sangatlah penting karena tanpa penjelasan rumusan secara operasional sulit untuk menentukan variabel-variabel yang relevan dengan masalah penelitian yang telah dirumuskan.

1. Jumlah Produksi (Y)

Jumlah Produksi yang dimaksud dalam penelitian ini yaitu jumlah hasil penjualan produk UMKM dalam setiap bulan yang dihitung dengan per-kemasan/unit. 


\section{Kredit (X1)}

Kredit yang dimaksud dalam penelitian ini yaitu jumlah dana yang diterima oleh pelaku UMKM setiap periode yang dihitung dengan satuan Rupiah (Rp).

3. Lama Usaha (X2)

Lama Usaha yang dimaksud dalam penelitian ini yaitu sudah berapa lamanya pengusaha ini menekuni usahanya yang dihitung dengan satuan Tahun.

4. Jumlah Pegawai (X3)

Jumlah Pegawai yang dimaksud dalam penelitian ini yaitu jumlah pegawai yang bekerja di UMKM tersebut yang dihitung dengan satuan orang.

\section{METODE ANALISIS DATA}

Analisis regresi

berganda igunakan untuk menganalisis besarnya hubungan dan pengaruh variabel independen yang jumlahnya lebih dari satu. Adapun bentuk persamaan regresi berganda adalah sebagai berikut (Suharyadi dan Purwanto, 2009).

$$
\begin{aligned}
& \mathrm{Y} 1=\beta_{0}+\beta_{1} \mathrm{X}_{1}+\beta_{2} \mathrm{X}_{2}+\beta_{3} \mathrm{X}_{3}+\mathrm{e} \\
& \text { Dimana }: \\
& \mathrm{Y} \quad=\text { Jumlah Produksi } \\
& \mathrm{X}_{1} \quad=\text { Kredit } \\
& \mathrm{X}_{2} \quad=\text { Lama Usaha } \\
& \mathrm{X}_{3} \quad=\text { Jumlah Pegawai } \\
& \beta_{0} \quad=\text { Konstanta } \\
& \beta_{1}, \beta_{2}, \beta_{3}=\text { Koefisien regresi } \\
& \mathrm{e} \quad=\text { Standar error }
\end{aligned}
$$

\section{Uji Asumsi Klasik}

Sebelum melakukan pengujian hipotesis, terlebih dahulu akan dilakukan pengujian terjadinya penyimpangan terhadap asumsi klasik. Dalam uji asumsi klasik terdapat beberapa pengujian yang harus dilakukan yakni Uji Multikolinieritas, Uji Heteroskedastisitas, dan Uji Normalitas.

Uji asumsi klasik dilakukan karena model regresi perlu memperhatikan adanya penyimpangan-penyimpangan atas asumsi klasik, karena pada dasarnya jika asumsi klasik tidak dipenuhi maka variabel-variabel yang menjelaskan akan menjadi tidak efisien. Pengujian asumsi klasi dalam penelitian ini meliputi uji normalitas, uji miltikolinearitas, dan heteroskedastisitas, dan apakah data dalam penelitian sudah berdistribusi secara normal atau belum. Karena apabila terjadi penyimpangan terhadap asumsi klasik maka uji $\mathrm{t}$ dan uji $F$ yang dilakukan sebelumnya tidak valid dan secara statistik dapat mengacaukan kesimpulan yang diperoleh (Widarjono, 2005).

\section{$\underline{\text { Uji Statistik }}$}

Pengujian hipotesis statistik dalam penelitian ini meliputi pengujian hipotesis secara parsial (Uji-t), dan pengujian ketetapan perkiraan $\left(\mathrm{R}^{2}\right)$. (Ghozali, 2011)

1. Pengujian Parsial (Uji-t)

Uji t digunakan untuk menentukan apakah variabel independen (X) berpengaruh secara parsial atau sendiri-sendiri terhadap variabel dependen (Y). Dimana thitung diperoleh dari hasil output Eviews sedangkan ttabel diperoleh dari statistik dengan melihat nilai signifikansi (a) dan degree of freedom. (Ghozali, 2011). 
Pengujian ini dilakukan berdasarkan perbandingan nilai thitung masing-masing koefisien regresi dengan nilai ttabel (nilai kritis) sesuai dengan tingkat signifikansi yang digunakan. Jika thitung > ttabel maka $\mathrm{H} 0$ ditolak dan H1 diterima atau ada hubungan yang signifikan.

2. Uji Signifikasi Simultan (Uji F)

Uji statistik $\mathrm{F}$ menunjukkan apakah semua variabel independen yang dimasukkan dalam model mempunyai pengaruh secara bersama-sama terhadap variabel dependen. (Ghozali, 2005).

3. Koefisien Determinasi $\left(\mathrm{R}^{2}\right)$

Koefisien determinasi adalah salah satu nilai statistik yang dapat digunakan untuk mengetahui apakah ada hubungan pengaruh antara dua variabel. Nilai koefisien determinasi menunjukan persentase variasi nilai variabel dependen yang dapat dijelaskan oleh persamaan regresi yang dihasilkan. Besarnya koefisien determinasi dari 0 sampai dengan 1. Semakin mendekati nol besarnya koefisien determinasi suatu persamaan regresi, maka semakin kecil pula pengaruh semua variabel independen terhadap nilai variabel dependen. Sebaliknya, semakin mendekati satu besarnya koefisien determinasi suatu persamaan regresi, maka semakin besar pula pengaruh semua variabel independen terhadap variabel dependen (Algifari, 1997:56).

Menurut Widarjono (2007:29), sebuah garis adalah baik jika $R$-square tinggi dan sebaliknya bila nilai $\mathrm{R}^{2}$ adalah rendah maka garis regresinya kurang baik. Meskipun $R$-square diperoleh dari hasil analisis rendahbukan berarti hasil penelitian tidak bagus. Namun demikian, kita harus memahami bahwa rendahnya $R$-square terjadi beberapa alasan. Dalam kasus khusus variabel independen (X) mungkin bukan variabel yang menjelaskan dengan baik terhadap variabel dependen (Y) walaupun kita percaya bahwa X mampu menjelaskan Y, hal ini terjadi karena adanya variasi yang besar antara variabel yang diteliti pada periode waktu yang sama.

\section{HASIL PENELITIAN}

\section{$\underline{\text { Hasil Uji Regresi Linier Berganda }}$}

Berdasarkan hasil output Eviews 9 tabel 4.7 maka dapat diketahui persamaanregresi linier berganda pada penelitian ini adalah sebagai berikut :

$\mathrm{Y}=-1,3458+0,5444 \mathrm{X}_{1}+0,1096 \mathrm{X}_{2}$ $-0,0999 X_{3}$

Persamaan diatas dapat dielaskan sebagai berikut :

1. $\quad \beta 0=-1,3458$

Nilai $-1,3458$ diartikan sebagai nilai jumlah produksi (Y). Jika kredit (X1), lama usaha (X2), dan jumlah pegawai (X3) dianggap 0 (nol) ataukonstan maka jumlah produksi (Y) akan sebesar -1,3458. Dapat disimpulkan apabila kredit, lama usaha, jumlah pegawai tidak mengalami perubahan maka jumlah produksi usaha mikro kecil menengah sebesar $-1,3458$.

2. $\quad \beta 1=0,5444$

Nilai 0,5444 artinya jika lama usaha (X2) dan jumlah pegawai (X3) konstan, maka jumlah kredit (X1) akan menyebabkan kenaikan jumlah 
produksi (Y) sebesar 0,5444. Dapat disimpulkan bahwa apabila jumlah kredit bertambah akan menyebabkan peningkatan jumlah produksi usaha mikro kecil menengah di Kota Tarakan sebesar 0,5444

\section{3. $\quad \beta 2=0,1096$}

Nilai 0,1096, artinya jika kredit (X1) dan jumlah pegawai (X3) konstan, maka lamanya suatu usaha (X2) akan menyebabkan kenaikan jumlah produksi (Y) sebesar 0,1096. Dapat disimpilkan bahwa semakin lama usaha mikro kecil menengah itu menyebabkan peningkatan jumlah produksi usaha mikro kecil menengah di Kota Tarakan sebesar 0,1096 .

\section{4. $\quad \beta 3=0,0999$}

Nilai 0,0999, artinya jika kredit (X1) dan lama usaha (X2) konstan, maka bertambahnya jumlah pegawai (X3) akan menyebabkan kenaikan jumlah produksi (Y) sebesar0,0999. Dapat disimpulkandengan bertambahnya jumlah pegawai akan menyebabkan peningkatan jumlah produksi usaha mikro kecil menengah di Kota Tarakan sebesar 0,0999.

\section{$\underline{\text { Hasil Uji-t }}$}

Berdasarkan hasil pengujian uji t-statistik, pengaruh kredit (X1) terhadap jumlah produksi usaha mikro kecil menengah (Y) diperoleh nilai t-statistik sebesar 3,5170 dengan nilai probabilitas sebesar 0,0010 dengan taraf signifikasi sebesar 0,05 dari hasil tersebut nilai t-statistik lebih besar dari t-tabel $(3,5170>1,6802)$ dan probabilitas tstatistik lebih kecil dari taraf signifikan $(0,0010<0,05)$. Sehingga dapat disimpulkan bahwa HA diterima dan Ho ditolak yang artinya kredit berpengaruh signifikan terhadap jumlah produksi usaha mikro kecil menengah di Kota Tarakan secara parsial.

Berdasarkan hasil pengujian uji t-statistik, lama usaha (X2) terhadap jumlah produksi usaha mikro kecil menengah (Y) diperoleh nilai t-statistik sebesar 4,3366 dengan nilai probabilitas sebesar 0,0001 dengan taraf signifikasi sebesar 0,05 dari hasil tersebut nilai t-statistik lebih besar dari t-tabel $(4,3366>1,6802)$ dan probabilitas tstatistik lebih kecil dari taraf signifikan $(0,0001<0,05)$. Sehingga dapat disimpulkan bahwa HA diterima dan Ho ditolak yang artinya lama usaha berpengaruh signifikan terhadap jumlah produksi usaha mikro kecil menengah di Kota Tarakan secara parsial.

Berdasarkan hasil pengujian uji t-statistik, jumlah pegawai (X3) terhadap jumlah produksi usaha mikro kecil menengah (Y) diperoleh nilai t-statistik sebesar $-1,4970$ dengan nilai probabilitas sebesar 0,1415 dengan taraf signifikasi sebesar 0,05 dari hasil tersebut nilai t-statistik lebih kecil dari t-tabel ($1,4970<1,6802)$ dan probabilitas $\mathrm{t}-$ statistik lebih besar dari taraf signifikan $(0,1415>0,05)$. Sehingga dapat disimpulkan bahwa HA ditolak dan Ho diterima yang artinya jumlah pegawai tidak berpengaruh signifikan terhadap jumlah produksi usaha mikro kecil menengah di Kota Tarakan secara parsial.

\section{$\underline{\text { Hasil Uji-F }}$}

Berdasarkan hasil pengujian bahwa nilai F-statistik lebih besar 
dari F-tabel $(22,6385>2,82)$ dan probabilitas F-statistik lebih kecil dari taraf signifikan $(0,0000<0,05)$. Sehingga dapat disimpulkan bahwa semua variabel bebas yaitu kredit, lama usaha, jumlah pegawai terhadap jumlah produksi usaha mikro kecil menengah di Kota Tarakan.

\section{$\underline{\text { Koefisien Determinasi }}$}

Dari hasil output data pada Eviews 9 maka koefisien determinasi $\left(\mathrm{R}^{2}\right)$ dalam penelitian ini adalah 0,6068 menunjukan bahwa variabel kredit, lama usaha, dan jumlah pegawai mampu menjelaskan variabel jumlah produksi usaha mikro kecil menengah di Kota Tarakan sebesar $60,68 \%$ sedangkan sisanya $30,32 \%$ dijelaskan oleh variabel lain yang tidak ada dalam model regresi.

\section{KESIMPULAN DAN SARAN}

$\underline{\text { Kesimpulan }}$

Berdasarkan uraian hasil penelitian analisis dan pembahasan, maka peneliti menyimpulkannya sebagai berikut:

1. Secara parsial diperoleh hasil:

a. Kredit berpengaruh signifikan terhadap jumlah produksi usaha mikro kecil menengah di Kota Tarakan.

b. Lama usaha berpengaruh signifikan terhadap jumlah produksi usaha mikro kecil menengah di Kota Tarakan.

c. Jumlah pegawai tidak berpengaruh signifikan terhadap jumlah produksi usaha mikro kecil menengah di Kota Tarakan.
2. Secara simultan, varibel bebas yaitu kredit, lama usaha, dan jumlah pegawai berpengaruh signifikan jumlah produksi usaha mikro kecil menengah di Kota Tarakan, secara simultan maka dalam penelitian ini hipotesis diterima.

\section{$\underline{\text { Saran }}$}

Adapun saran terkait dengan penelitian ini adalah :

1. Hasil penelitian ini menjadi referensi bagi pelaku usaha khususnya usaha mikro kecil menengah untuk meningkatkan hasil produksi

2. Peneliti selanjutnya dapat menganalisis variabel-variabel lain yang mempengaruhi produktivitas

\section{DAFTAR PUSTAKA}

Hendriksen, 2000. Teori Akuntansi, Terjemahan Hermawan Wibowo, Edisi

5.Jakarta: Intraksara.

Hill, Hal. "Small and Medium Enterprises In Indonesia : Old Policy Chaillenges for a New Administration ". Asian Survey XLI no.2 (April 2001).

Kasmir, 2004. Bank dan Lembaga Keuangan Lainnya Edisi Keenam, Jakarta : PT Raja Grafindo Persada.

Kementerian Negara Koprasi dan Usaha Mikro

Kecil Menengah Tahun 2012. Jenis Usaha Mikro Kecil Menengah $\quad$ di Indonesia. 
Mulyadi, 1999. Akuntansi Biaya Edisi 5. Yogyakarta : Aditya Medika.

Struyk, Raymond J. 2011.

Which Indonesian Small and Medium Firms

UseFormal Financial

Services?. Journal

Of Economic and

Finance, Vol 3 No.4.

Sugiyono, 2009. Metode Penelitian

Kuantitatif, Kualitatif

dan R\&B, Bandung:

Alfabeta.

Suharyadi \& Perwanto. 2009.

Statistika Untuk

Ekonomi dan Keuangan

'Modern, Jakarta: Salemba

Empat

Sukirno, $\quad$ Sadono. 1994.

Pengantar Teori

Ekonomi Makro, PT

Raja Grafindo,

Jakarta. Suparmoko,

2000. Keuangan Negara

Dalam Teori Dan Praktek,

BPFE Yogyakarta.

Tambunan, Tulus, 2002. Usaha

Kecil dan Menengah di

Indonesia : BeberapaIsu

Penting, Penerbit Salemba Empat, Jakarta.

Undang-undang Ketenaga

Kerjaan No.13 Tahun

2003. Definisi Upah Undang-undang

Usaha Mikro Kecil dan

Menengan No.30 Tahun

2008. Definisi Usaha Mikro

Kecil dan Menengah.

Widarjono, Agus, 2007.

Ekonometrika Teori dan

Aplikasi. Yogyakarta:

Ekonosia.

Yudaruddin, Rizky, 2014. Analisis

Konsumsi: Profektif Ekonomi
Islam. Jurnal Ekonomi dan

Studi Pembangunan. 
